\section{Editorial}

\section{*Corresponding author \\ Mizrahi Meir, MD}

Division of Gastroenterology

Center for Advanced Endoscopy

Beth Israel Deaconess Medical Center

and Harvard Medical School

330 Brookline Ave., Boston

MA 02215, USA

E-mail: mmizrahi@bidmc.harvard.edu

Volume 1 : Issue 2

Article Ref. \#: 1000GOJ1e001

\section{Article History}

Received: April 15th 2015

Accepted: April 15 $5^{\text {th }}, 2015$

Published: April 17 $7^{\text {th }}, 2015$

\section{Citation}

Benson AA, Mizrahi M. Endoscopy: from diagnosis to therapeutics. Gastro Open J. 2015; 1(2): e1-e3. doi: 10.17140/GOJ-1-e001

\section{Copyright}

(C2015 Mizrahi M. This is an open access article distributed under the Creative Commons Attribution 4.0 International License (CC BY 4.0), which permits unrestricted use, distribution, and reproduction in any medium, provided the original work is properly cited.

\title{
Endoscopy: From Diagnosis to Therapeutics
}

Ariel A. Benson ${ }^{1}$ and Mizrahi Meir ${ }^{*}$

${ }^{1}$ Division of Medicine, Institute of Gastroenterology and Liver Diseases, Hadassah-Hebrew University Medical Center, Jerusalem, Israel

${ }^{2}$ Division of Gastroenterology, Center for Advanced Endoscopy, Beth Israel Deaconess Medical Center and Harvard Medical School, 330 Brookline Ave., Boston, MA 02215, USA

Two decades ago, gastroenterologists used endoscopy for the diagnosis of Gastrointestinal (GI) lesions, thereby helping surgeons to localize lesion that necessitated resection and treatment with surgery. Today, the gastroenterology field has advanced beyond the diagnostic era and now, a large number of GI lesions can be treated via endoluminal procedures performed by the gastroenterologist with no need for surgical intervention.

In recent years, the improvement of endoscopic imaging and tools, such as snares, clips and needles which can be delivered through the endoscope channel, have helped to change the field of gastroenterology. This allowed for the development and advancement of Endoscopic Mucosal Resection (EMR) and Endoscopic Submucosal Dissection (ESD). The pioneers of EMR and ESD were from Japan and the first articles describing these techniques were published in the 1990s. ${ }^{1,2}$

Two classification systems are used for describing GI lesions to be considered for EMR and ESD. One system is the Japanese classification ${ }^{3}$ and the second is the Paris system, which was proposed in 2002. ${ }^{4}$ The Japanese classification was originally developed for early gastric cancer management, but it can be applied to lesions throughout the GI tract. Once lesions are classified, EMR can be performed in different GI locations, including the esophagus, stomach, colon and rectum. When lesions are more complex and beyond the mucosa, ESD can be performed with careful dissection.

Endoscopic ultrasound (EUS) may be useful in deciding whether to perform EMR or ESD. EUS can aid in determining the penetration of the tumor to layers beyond the mucosa when the lesion is localized in proximal parts of the colon. If the lesion cannot be reached by a regular EUS endoscope special high frequency mini-probes may be used through the colonoscope working channel.

Two methods are used in performing EMR. The first method is 'suck and cut' and the second method is 'lift and cut'. Both usually begin with a submucosal injection prior to resection of the lesion the suc and cut method may be used also without submucosal injection especially when being performed in the esophagus. The injection is used to expand the submucosa, separating the deeper muscolaris propria from the more superficial mucosa and submucosa layers. Several solutions may be used as the injectate. These include normal saline with or without diluted epinephrine, hypertonic saline, dextrose solution, sodium hyaluronate, fibrinogen combination, glycerol, and fructose solutions all of those may be mixture with methylene blue depend on the preference of the endoscopist..$^{5-8}$ Conio, et al. compared the solutions and showed that the disappearing time of normal saline is approximately 3 minutes with or without epinephrine, while the disappearing times of $50 \%$ dextrose and $10 \%$ glycerol and hyaluronic acid solutions were $4.7,4.2$ and 22 minutes respectively. ${ }^{9}$

After injection, one of the two resection methods can be applied. The 'suck and cut' 


\section{GASTRO}

method utilizes a transparent cap on the endoscope and requires suctioning of the lesion into the cap. The lesion is then resected by a snare which exits through the working channel into the transparent cap. A variation of this method is the use of bands instead of an injection solution, and this method is best for the treatment of esophageal lesions. ${ }^{10}$ Following injection, the "lift and cut' method involves the use of a grasper to pull the lesion from the muscolaris propria. The 'lift and cut' method was the first EMR technique, but because of complexity, the 'suck and cut' method is now used more widely.

When the lesion is thought to be deeper or wider, if it is a submucosal lesion, or if en bloc resection is preferred, ESD may be used for resection. ESD includes the same inject and lift method as EMR, but instead of using a snare, needle knife is used to resect the lesion through dissection. ESD can be performed in different GI locations such as esophagus, stomach, duodenum, colon and rectum.

Once removal of the lesion is complete, tattooing of the procedure area can be considered in order to assist in surveillance. Use of India ink tattooing is recommended, but careful injection is necessary as India ink can result in tissue scarring if injected to the submucosal space. One method to prevent scarring is to first inject normal saline to separate the mucosa and the submucosal layers and then inject the ink.

The long term outcomes of both EMR and ESD have been positive. Merkow, et al. compared the outcomes of patients with early esophageal cancer treated by EMR or surgery. There was a higher 30 day mortality rate in the surgical group and 5 year survival was $77 \%$ and $88 \%$ in the EMR and surgical groups respectively. ${ }^{11}$ EMR for gastric lesions (when the margins of the lesion are clear with no dysplasia) has also had favorable outcomes. The outcomes of colonic EMR for early colon cancer are similar to the results in esophageal and gastric EMR. Bledebos, et al. reported the results of a meta-analysis of colonic EMR showing that the recurrence rate was $15 \%$ and that piecemeal resection had a higher recurrence rate as compared to en bloc resection ( $20 \%$ versus $3 \%$ respectively)..$^{12}$ Ikematsu, et al. reported long term outcomes after resection of submucosal invasive colorectal cancer by ESD or surgery. In patients with low risk lesions (lesion entirely resected, well to moderately differentiated adenocarcinoma, no vascular invasion and submucosal invasion $<1 \mathrm{~mm}$ ), there were recurrence rates of $0 \%$ and $6 \%$ for rectal and colonic lesions, while in patients with high risk lesions, the recurrence rates were $1.4 \%$ and $16 \%$ for rectal and colonic lesions respectively. ${ }^{13}$

Both EMR and ESD can lead to adverse events and in order to lower complication rates the procedures should be performed by experienced endoscopists. Adverse events, including perforations, strictures, and immediate or late bleeding during esophageal EMR were reported to be present in $0 \%$ to $13 \%$ of cases. ${ }^{14,15}$ Gastric EMR adverse events have been reported to range from $1 \%$ to $5 \% .^{16,17}$ In colonic EMR, bleeding events may occur in as many as $24 \%$ of cases. ${ }^{18}$ Colonic ESD may be complicated by perforation in up to $10 \%$ of cases as reported by Tamegai $\mathrm{Y}$, et al. ${ }^{19}$ but in most cases the perforation may be treated endoscopically without the need for surgical intervention.

In conclusion, EMR and ESD will continue to be performed worldwide, likely with increased frequency, during the next several years. Nonetheless, in order to avoid and reduce complications, it is recommended that EMR and ESD be performed at high volume centers and by experienced endoscopists.

\section{CONFLICTS OF INTEREST: None.}

\section{REFERENCES}

1. Hamada T, Kondo K, Itagaki Y, Nishida J. Endoscopic mucosal resection for early gastric cancer. Nihon Rinsho. 1996; 54: 1292.

2. Endo M, Takeshita K, Inoue H. Endoscopic mucosal resection of esophageal cancer. GanTo Kagaku Ryoho. 1995; 22: 192.

3. Kajitani T. The general rules for The gastric cancer study in surgery pathology. Part I. Clinical classification. Jpn J Surg. 1973; 3: 61 .

4. Paris Workshop Participants. The Paris endoscopic classification of superficial neoplastic lesions: esophagus, stomach, and colon: November 30 to December 1, 2002. GastrointestEndosc. 2003; 58: S3. doi: 10.1016/S0016-5107(03)02159-X

5. Fujishiro M, Yahagi N, Kashimura K, et al. Comparison of various submucosal injection solutions for maintaining mucosal elevation during endoscopic mucosal resection. Endoscopy. 2004; 36: 579. doi: 10.1055/s-2004-814517

6. Lee SH, Park JH, Park do H, et al. Clinical efficacy of EMR with submucosal injection of a fibrinogen mixture: a prospective randomized trial. GastrointestEndosc. 2006; 64: 691. doi: 10.1016/j.gie.2006.07.032

7. Yamamoto H, Yahagi N, Oyama T, et al. Usefulness and safety of $0.4 \%$ sodium hyaluronate solution as a submucosal fluid "cushion" in endoscopic resection for gastric neoplasms: a prospective multicenter trial. GastrointestEndosc. 2008; 67: 830. doi: 10.1186/1471-230X-9-1

8. Feitoza AB, Gostout CJ, Burgart LJ, et al. Hydroxypropyl methylcellulose: A better submucosal fluid cushion for endoscopic mucosal resection. GastrointestEndosc. 2003; 57: 41. doi: $10.1067 / \mathrm{mge} .2003 .25$

9. Conio M, Rajan E, Sorbi D, et al. Comparative performance in the porcine esophagus of different solutions used for submu- 
cosal injection. GastrointestEndosc. 2002; 56: 513. doi: 10.1067/ mge.2002.128107

10. Fleischer DE, Wang GQ, Dawsey S, et al. Tissue band ligation followed by snare resection (band and snare): a new technique for tissue acquisition in the esophagus. GastrointestEndosc. 1996; 44: 68. doi: 10.1016/S0016-5107(96)70233-X

11. Merkow RP, Bilimoria KY, Keswani RN, et al. Treatment trends, risk of lymph node metastasis, and outcomes for localized esophageal cancer. J Natl Cancer Inst. 2014; 106(7): diu133. doi: 10.1093/jnci/dju133

12. Belderbos TD, Leenders M, Moons LM, Siersema PD. Local recurrence after endoscopic mucosal resection of nonpedunculated colorectal lesions: systematic review and meta-analysis. Endoscopy. 2014; 46: 388. doi: 10.1055/s-0034-1364970

13. Ikematsu H, Yoda Y, Matsuda T, et al. Long-term outcomes after resection for submucosal invasive colorectal cancers. Gastroenterology. 2013; 144: 551. doi: 10.1053/j.gastro.2012.12.003

14. Li QL1, Yao LQ, Zhou PH, et al. Submucosal tumors of the esophagogastric junction originating from the muscularispropria layer: a large study of endoscopic submucosal dissection. GastrointestEndosc. 2012; 75(6): 1153-1158. doi: 10.1016/j. gie.2012.01.037

15. Tomizawa Y1, Iyer PG, Wong Kee Song LM, Buttar NS, Lutzke LS, Wang KK. Safety of endoscopic mucosal resection for Barrett's esophagus. Am J Gastroenterol. 2013; 108(9): 1440-1447.

16. Park YM, Cho E, Kang HY, Kim JM. The effectiveness and safety of endoscopic submucosal dissection compared with endoscopic mucosal resection for early gastric cancer: a systematic review and metaanalysis. SurgEndosc 2011; 25: 2666. doi: 10.1038/ajg.2013.187

17. Okano A, Hajiro K, Takakuwa H, et al. Predictors of bleeding after endoscopic mucosal resection of gastric tumors. GastrointestEndosc. 2003; 57: 687. doi: 10.1067/mge.2003.192

18. Ahmad NA, Kochman ML, Long WB, et al. Efficacy, safety, and clinical outcomes of endoscopic mucosal resection: a study of 101 cases. GastrointestEndosc. 2002; 55: 390. doi: 10.1067/ mge.2002.121881

19. Tamegai Y, Saito Y, Masaki N, et al. Endoscopic submucosal dissection: a safe technique for colorectal tumors. Endoscopy. 2007; 39: 418. doi: 10.1055/s-2007-966427 